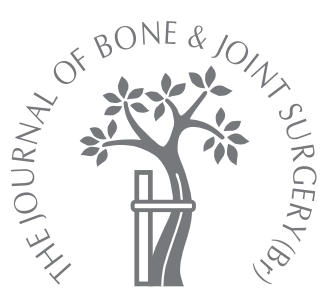

J. Iwasa, M. Ochi, Y. Uchio, N. Adachi, K. Kawasaki

From Shimane University School of Medicine, Izumo, Japan

\title{
Decrease in anterior knee laxity by electrical stimulation of normal and reconstructed anterior cruciate ligaments
}

In. Iwasa, MD, PhD, Assistant Professor

- Y. Uchio, MD, PhD, Professor and Chairman

K. Kawasaki, MD, PhD, Assistant Professor Department of Orthopaedic Surgery

Shimane University School of Medicine, 89-1 Enya, Izumo, Shimane 693-8501, Japan.

M. Ochi, MD, PhD, Professor and Chairman

n. Adachi, MD, PhD,

Assistant Professor

Department of Orthopaedic

Surgery

Programs for Applied

Biomedicine, Division of

Clinical Medical Sciences

Hiroshima University,

Hiroshima 734-8551, Japan.

Correspondence should be sent to Dr J. Iwasa; e-mail: j-iwasa@ med.shimane-u.ac.jp

(c)2006 British Editorial Society of Bone and Joint Surgery doi:10.1302/0301-620X.88B4. $17186 \$ 2.00$

$J$ Bone Joint Surg [Br] 2006;88-B:477-83.

Received 14 September 2005; Accepted 5 January 2006

We have investigated the changes in anterior laxity of the knee in response to direct electrical stimulation of eight normal and $\mathbf{4 5}$ reconstructed anterior cruciate ligaments (ACLs). In the latter, the mean time from reconstruction was 26.7 months (24 to 32). The ACL was stimulated electrically using a bipolar electrode probe during arthroscopy. Anterior laxity was examined with the knee flexed at $20^{\circ}$ under a force of $134 \mathrm{~N}$ applied anteriorly to the tibia using the KT-2000 knee arthrometer before, during and after electrical stimulation.

Anterior tibial translation in eight normal and 17 ACL-reconstructed knees was significantly decreased during stimulation, compared with that before stimulation. In 28 knees with reconstruction of the $A C L$, in 22 of which the grafts were found to have detectable somatosensory evoked potentials during stimulation, anterior tibial translation was not decreased. These findings suggest that the ACL-hamstring reflex arc in normal knees may contribute to the functional stability and that this may not be fully restored after some reconstructions of the $A C L$.

Current attention on the function of mechanoreceptors in the anterior cruciate ligament (ACL) is a resurgence of interest in a mechanism which had been suggested many years ago. Mechanoreceptors have been demonstrated in the human ACL in a number of studies. $^{1-3}$ Investigation of proprioception in patients without a functioning ACL has shown deficits in joint position sense $\mathrm{e}^{4-7}$ and kinesthesia. ${ }^{5,8-10}$ During arthroscopy, Pitman et $\mathrm{al}^{11}$ demonstrated somatosensory evoked potentials in the cerebral cortex after direct electrical stimulation of an intact ACL in nine patients, indicating proprioceptive input transmitted along the posterior columns from peripheral nerves.

Furthermore, various authors have suggested that the ACL functions as a sensory organ, providing proprioceptive information and initiating protective and stabilising muscle reflexes. $^{12}$ Solomonow et $\mathrm{al}^{13}$ demonstrated reflex contraction of the hamstrings when mechanical stress was applied to the ACL in cats. Other experimental evidence ${ }^{14,15}$ has suggested that stimulation of ligamentous mechanoreceptors may lead to reflex muscle activation. In humans, Dyhre-Poulsen and Krogsgaard ${ }^{16}$ and Tsuda et $\mathrm{al}^{17}$ found evidence of a direct reflex between the ACL and muscles acting on the knee. While a direct ACL- hamstring protection system may be difficult to demonstrate in animal and human models, there is increasing evidence indicating the existence of a proprioceptive mechanism which arises from the ACL and influences tone in the thigh muscles. The ACL-hamstring reflex may therefore play a physiological role in knee kinematics. However, it is uncertain whether the ACL-hamstring reflex is involved in maintaining stability of the knee.

Reconstruction of the ACL using autogenous grafts of either bone-patellar tendonbone, or hamstring tendon has produced a good to excellent outcome based on clinical assessment. ${ }^{18,19}$ Improvement in the dynamic stability of the knee, reduced joint laxity and improved proprioception as the graft heals, may be associated with a successful functional outcome. It has been suggested that mechanoreceptors can regenerate within the ACL in animal models. ${ }^{1,20-22}$ In humans, we have previously ${ }^{23,24}$ found detectable somatosensory evoked potentials (SEPs) after electrical and mechanical stimulation in the ACL reconstructed with autogenous hamstring tendons, suggesting that sensory reinnervation may occur in the reconstructed ACL and that reconstruction results in restoration, not only of a mechanical restraint, but also of function within the knee. 
Table I. Details of the patients in the two groups

\begin{tabular}{lcccll}
\hline & $\begin{array}{l}\text { Number of } \\
\text { patients }\end{array}$ & Male:Female & Right:Left & $\begin{array}{l}\text { Mean age } \\
\text { in yrs (SD) }\end{array}$ & $\begin{array}{l}\text { Activity score } \\
\text { (SD) }\end{array}$ \\
\hline Normal & 8 & $4: 4$ & $4: 4$ & $27.9(7.5)$ & $5.1(1.0)$ \\
ACL-reconstructed & 45 & $22: 23$ & $22: 23$ & $29.2(6.8)$ & $5.3(0.9)$ \\
\hline
\end{tabular}

It is not known whether the ACL-hamstring reflex is fully restored after reconstruction. If it is, then the matured, reinnervated graft would generate protective reflexes to prevent re-injury and progressive laxity, as suggested by Kennedy, Alexander and Hayes. ${ }^{25}$ Recently, Tsuda et $\mathrm{al}^{26}$ have demonstrated an increase in electromyographic activity in biceps femoris after electrical stimulation of the patellar tendon graft, indicating re-establishment of the ACL-hamstring reflex in the human knee after reconstruction of the ACL. If this reflex is fully restored, it should play the same role in maintaining stability as in the normal knee, but we do not know to what extent it has the same functional importance as in the normal knee.

It is, therefore, essential to determine whether the regenerated receptors can still provide neurophysiological function and contribute to functional stability. Using our previous technique, ${ }^{23}$ we selectively activated the sensory nerve fibres in the normal and reconstructed ACL by electrical stimuli and recorded subsequent changes in the anterior laxity of the knee with a KT-2000 knee arthrometer (MED Metric Corporation, San Diego, California). This device has been used extensively clinically to measure relative displacement and has been assessed for reliability, validity, and responsiveness to change. ${ }^{27}$ Our hypothesis was that electrical stimulation of the normal and reconstructed ACL would increase the stiffness of the knee through the ACL-hamstring reflex.

\section{Patients and Methods}

Two groups were recruited for this investigation, one with a normal ACL and the other, which had all undergone reconstruction of the ligament. Table I summarises the details of each group. Each had a similar age and recreational level. All patients gave consent and the protocol was approved by the Ethical Board of our institution. The normal ACL group consisted of four men and four women with a mean age of 27.9 years (14 to 39 ). All had undergone arthroscopy; for a superficial chondral lesion in four knees, for meniscal injury in two and for other internal derangements of the knee but without abnormality of the ACL in two. The group with reconstruction of the ACL comprised 22 men and 23 women with a mean age of 29.2 years ( 15 to 41 ) and a mean time from reconstruction of 26.7 months (24 to 32). They had all undergone arthroscopic reconstruction of the ligament with quadrupled semitendinosus or doubled semitendinosus and gracilis tendon grafts by an experienced arthroscopic surgeon (MO). All had normal contralateral knees and no history of previous injury, symptoms or neurological abnormality.
Stability, muscle strength, and joint position sense. The anterior laxity of each reconstructed knee was examined on the day before the experiment, using a KT-2000 knee arthrometer (MED Metric Corporation) with a force of 89 $\mathrm{N}$ applied posteriorly to the tibia as well as $134 \mathrm{~N}$ anteriorly, with the knee flexed at $20^{\circ}$. Both knees were examined and any difference in stability was recorded in millimetres as laxity.

The muscle strength in the ipsilateral quadriceps and hamstring muscles was determined by a Cybex 6000 dynamometer (Lumex Inc., Ronkonkoma, New York) at $60 \%$ s. The ratio of peak torque in the muscles of the surgically treated to that in the normal knee was estimated.

Evaluation of proprioception was performed according to the method of Skinner et $\mathrm{al}^{28}$ with modifications. The position sense of the knee was tested by examining the ability of patients to reproduce the angle at which the joint had been placed before being moved. In all the tests, patients were dressed in shorts without shoes or socks. The subjects were seated in a Cybex II dynamometer (Lumex Inc.) chair, with the seat adjusted to approximately $5 \mathrm{~cm}$ from the popliteal fossa and were asked to relax their legs completely. Their feet did not touch the floor. The patients were blindfolded to eliminate visual input and to facilitate concentration during testing. The examiner held an inflated air splint positioned around the patient's foot to reduce cutaneous sensory input to the lower limb and moved one of the legs at a slow, steady rate of $10^{\circ}$ per second. The starting reference position was $90^{\circ}$ of knee flexion. The ability to reproduce a passive knee position actively at five different target angles between $5^{\circ}$ and $25^{\circ}$ of flexion from the reference position was tested at intervals of $5^{\circ}$. The limb was held in this position for three seconds and the subjects were asked to concentrate on the positions at which their legs had been placed. The knee was returned to the starting angle and the subject was asked to position the leg at the targeted angle. The difference between the perceived angle and the actual angle of flexion, in degrees, was recorded as an inaccuracy. A measurement of inaccuracy between the perceived angle and the actual angle was recorded with the same positive sign for errors of both flexion and extension. The mean inaccuracies were recorded in both the injured and normal knees. The reproducibility of the measurements had been established previously, ${ }^{29,30}$ using the Bland and Altman plot showing the mean difference $(95 \%$ confidence intervals) of measurements in subjects to be $-0.14(-1.83$ to 1.56).

Somatosensory evoked potential (SEPs). All patients were anaesthetised using nitrous oxide and oxygen for induc- 


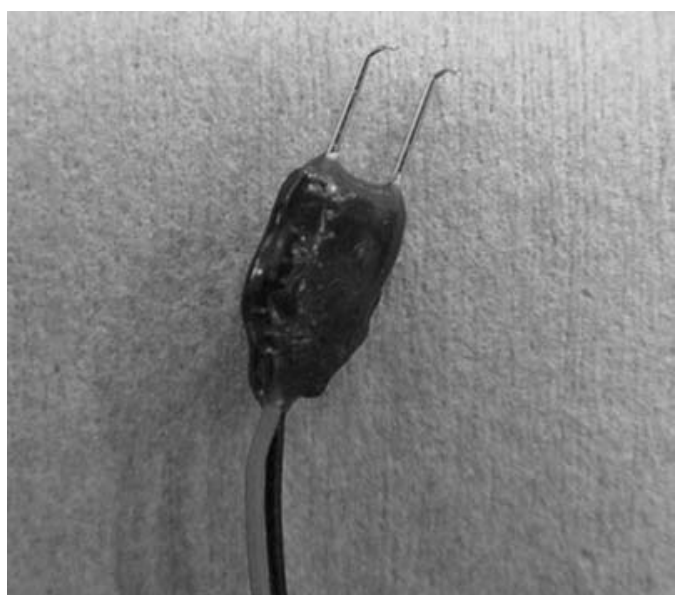

Fig. 1

Photograph of the electrode probe. The tip was bent to form a $1 \mathrm{~mm}$ hook to prevent it from displacement after insertion.

tion, followed by spontaneous respiration through a laryngeal mask. Inhaled anaesthetic agents such as halothane, isofluorane and enflurene were not used because of their depressant effects on the cortical response and motor units, alterations in reflex recruitment and on twitch responses. ${ }^{31,32}$ No local anaesthesia or epinephrine was used and neither were muscle relaxants.

The ACL was stimulated electrically by a bipolar electrode probe with a Teflon-coated tip (AU-1; InterMedical Co Ltd, Tokyo, Japan; Fig. 1), inserted into the anterior aspect of the midportion of the graft through an anteromedial portal (Fig. 2). In order to minimise variations, only one investigator (JI) determined the point at which the electrode was inserted. The stimulus came only from the extreme tip of the probe and did not spread through the synovial fluid or physiological saline to other structures of the knee.

The stimulus used was a square wave, $0.2 \mathrm{~ms}$ in duration, at an intensity of $10 \mathrm{~mA}$, with a rate of $3 / \mathrm{s}$. Electrode impedance was maintained at between $2 \mathrm{k} \Omega$ and $10 \mathrm{k} \Omega$. The room temperature was maintained at between $23^{\circ} \mathrm{C}$ and $25^{\circ} \mathrm{C}$. The cortical response was recorded over a bandwidth of 0.5 to $1500 \mathrm{~Hz}$ for a duration of $100 \mathrm{~ms}$. The mean of 200 epochs was recorded, with two responses being recorded for each trial and superimposed to ensure consistency with a measurement system for evoked potentials (Synax 1100; NEC Medical Systems, Tokyo, Japan).

The SEPs were monitored by a surface electrode placed on the shaved scalp at a point $2 \mathrm{~cm}$ lateral and $2 \mathrm{~cm}$ posterior to the $\mathrm{CZ}$ position, according to the international 10 to 20 system with reference to the FP and ear. In order to determine the reproducibility of measurement of the SEP, the recording was repeated at least twice. A result was considered to be positive if a response could be seen within a

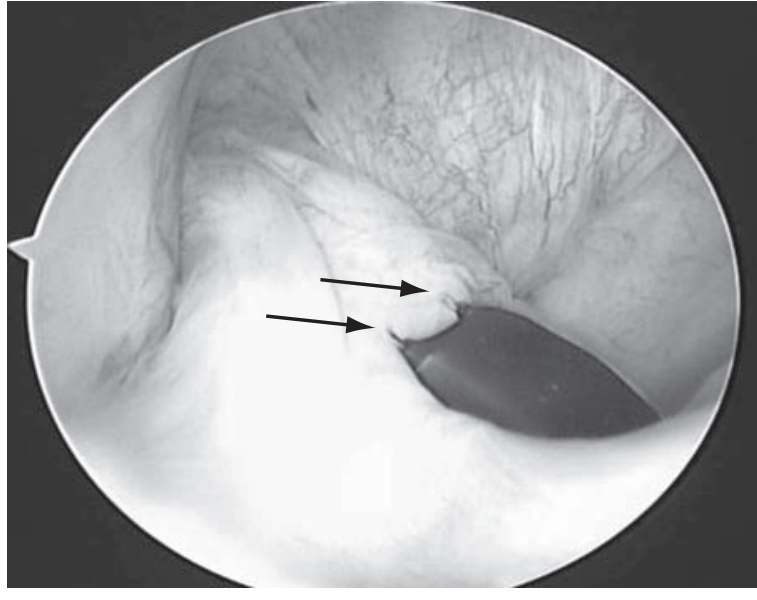

Fig. 2

Arthroscopic view of the tip of the bipolar electrode probe, inserted through the anteromedial portal and into the mid-portion of the hamstring tendon graft, transplanted as the ACL substitute. The arrows indicate the tip of the electrode.

reading and could be reproduced on a second reading. The higher voltage was selected as being the most representative of recorded SEPs. A result was considered to be negative if there was no response within the first or second reading or if there was inconsistency between the two. A third reading was then taken to ensure that there was no response or inconsistency with the first two. A peak or trough in each SEP, usually a P1 trough or N1 peak, was chosen as the feature for programmed automatic detection for a monitoring session. The latencies of P1 and N1 and the difference in potentials between P1 and N1 were calculated as the voltage of the SEP.

Measurement of anterior laxity. After the monitoring of the SEP, the arthroscope and saline were removed, leaving the electrode probe in the capsule of the knee joint. Care was taken to leave no saline within the knee. Anterior laxity was examined with the knee flexed at $20^{\circ}$ under a force of $89 \mathrm{~N}$ applied posteriorly to the tibia as well as $134 \mathrm{~N}$ anteriorly, using the KT-2000 knee arthrometer (MED Metric Corporation) before, during and after electrical stimulation (Fig. 3 ). The ligament was electrically stimulated in the same way as for monitoring the SEPs. In order to minimise variations, measurement of anterior laxity was carried out only by one experienced examiner $(\mathrm{KK})$. Anterior tibial translation in millimetres was evaluated at $134 \mathrm{~N}$. We took the mean of three tests to be the score. We recorded each test and the mean to the nearest $0.1 \mathrm{~mm}$, rather than the customary $0.5 \mathrm{~mm}$. Anterior terminal stiffness, in Newtons per $\mathrm{mm}$, was measured by drawing a line at the point of $134 \mathrm{~N}$ $(13.59 \mathrm{~kg})$ of loading on a force-displacement curve.

After the measurement of anterior laxity, we arthroscopically confirmed that the electrodes had been placed correctly. In a previous study, Jensen et al ${ }^{33}$ observed that once an electrode had been placed in the ligament, movement of 


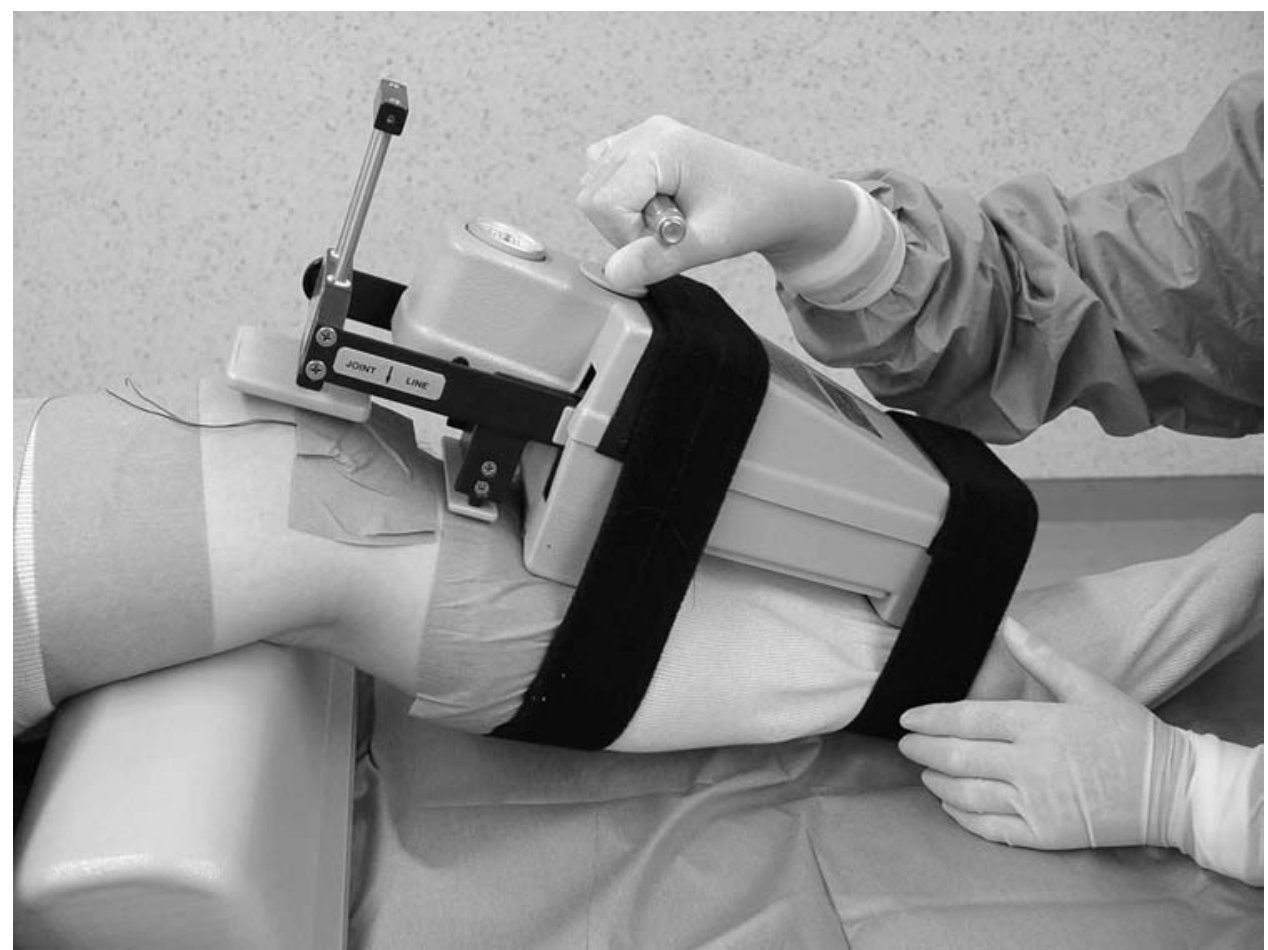

Fig. 3

Photograph showing the positions of the examiner and subject during measurement with the KT-2000 knee arthrometer to quantify anterior tibial translation and anterior terminal stiffness.

Table II. Stability, muscle strength and joint position sense in the two groups

\begin{tabular}{|c|c|c|c|}
\hline & Normal & $\begin{array}{l}\text { Anterior cruciate } \\
\text { ligament-reconstructed }\end{array}$ & p value \\
\hline Mean (SD) anterior displacement (side-to-side difference, mm) & $0.1(1.3)$ & $1.2(1.7)$ & 0.07 \\
\hline Mean (SD) hamstring muscle strength (ratio of peak torque, \%) & $91.8(8.0)$ & $90.0(14.2)$ & 0.87 \\
\hline Mean (SD) quadriceps muscle strength (ratio of peak torque, \%) & $89.8(7.6)$ & $88.7(13.5)$ & 0.83 \\
\hline Mean (SD) joint position sense inaccuracy of the operated knee $\left({ }^{\circ}\right)$ & $3.60(1.04)$ & $3.88(1.27)$ & 0.56 \\
\hline
\end{tabular}

the joint did not displace it, whereas traction would easily do so. Therefore, we bent the tip to form a $1 \mathrm{~mm}$ hook to prevent displacement after insertion into the ligament (Fig. 1), thus ensuring that any change in anterior terminal stiffness or anterior tibial translation recorded from the knees was due to the stimulation of the nerve fibres in the ACL and not because of excitation of reflexes from the joint capsule or muscle strength receptors.

Reproducibility of the KT-2000 knee arthrometer. A pilot study was carried out to determine the magnitude of the trial-totrial variability of anterior knee laxity measurements in normal individuals within a test. An interclass correlation coefficient was used to determine the intraobserver reliability for the KT-2000 $(\mathrm{n}=12)$. The examiner $(\mathrm{KK})$ proved to be reliable over time, with an intraclass correlation coefficient of $0.96(\mathrm{p}<0.0001)$.
Statistical analysis. All numerical data were expressed as the mean and SD. The paired $t$-test was used to verify the statistical significance of differences in anterior laxity before, during and after electrical stimulation. The results between the normal ACL group and those with reconstruction of the ACL were compared statistically using the unpaired $t$-test and repeated measures of analysis of variance. A p value of less than 0.05 was considered to be statistically significant.

\section{Results}

The stability, muscle strength, and joint position sense of the knee. All patients with reconstruction of the ACL had excellent or good outcomes, category A or B International Knee Documentation Committee scores, ${ }^{34}$ and a KT-2000 side-to-side difference of $4.5 \mathrm{~mm}$ or less (Table II). There 
Table III. Details of the mean SEP* (SD) after electrical stimulation of the $\mathrm{ACL}^{\dagger}$ in both groups. A reproducible SEP was previously established with a trough (P1) and a peak (N1) in the initial component of the response. The number in parentheses represents the patients with a detectable SEP

\begin{tabular}{llll}
\hline & \multicolumn{2}{l}{ Latency $(\mathrm{ms})$} & $\begin{array}{l}\text { Voltage } \\
\text { (P1N1 }(\mu \mathrm{V}))\end{array}$ \\
\cline { 2 - 3 } & $\mathbf{P 1}$ & N1 & \\
\hline Normal $(\mathrm{n}=8)$ & $35.5(4.9)$ & $52.5(4.5)$ & $1.55(0.41)$ \\
ACL reconstruction $(\mathrm{n}=39)$ & $35.3(5.4)$ & $54.8(6.1)$ & $1.46(0.39)$
\end{tabular}

* SEP, somatosensory evoked potential

$+\mathrm{ACL}$, anterior cruciate ligament

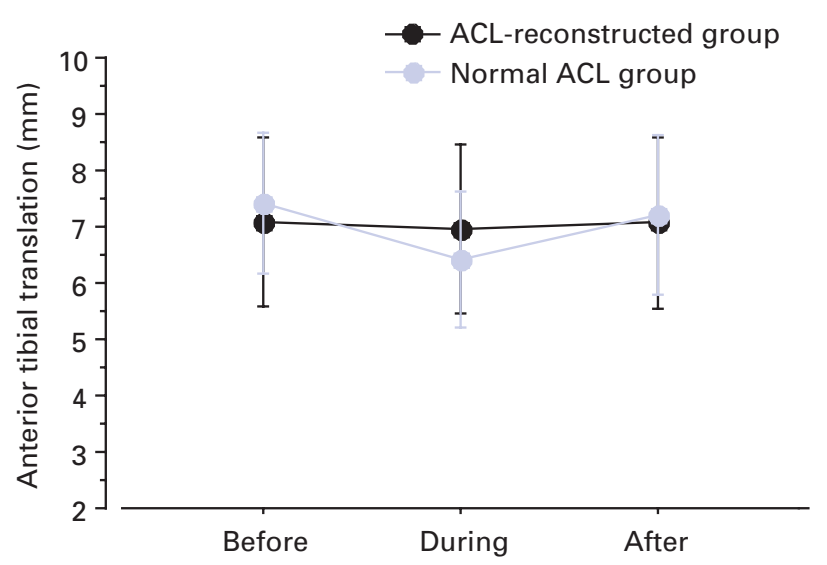

Electrical stimulation

Fig. 4

Graph showing the change in anterior tibial translation. The anterior tibial translation in normal knees during stimulation was significantly decreased compared with that before stimulation, according to the paired $t$-test $(\mathrm{p}<0.001)$. A significant time-related difference was also found between the two groups according to repeated-measures analysis of variance $(p<0.001)(A C L$, anterior cruciate ligament).

were no significant differences between the groups in the strength of the hamstring muscle $(\mathrm{p}=0.87)$ and the quadriceps $(\mathrm{p}=0.83)$. In addition, no significant difference was found between the two groups in inaccuracy of the joint position sense of the operated knee $(p=0.56)$.
SEPs induced by electrical stimulation of the ACL. Reproducible cortical SEPs were detected in all eight knees in the normal group and in 39 of 45 knees in those with a reconstruction. Table III shows the observations of the P1 and N1 latencies and the voltage of the SEP obtained after stimulation of the ACL.

Measurement of anterior knee laxity. The mean anterior tibial translation values before, during and after stimulation of the ACL in the normal group were $7.4 \mathrm{~mm}$ (SD 1.3), $6.4 \mathrm{~mm}$ (SD 1.2) and $7.2 \mathrm{~mm}$ (SD 1.4), respectively. The anterior tibial translation in all normal knees during stimulation was significantly decreased $(\mathrm{p}<0.001)$, compared with that before stimulation (Fig. 4). The mean anterior tibial translation values before, during and after stimulation of the ACL in the reconstruction group were $7.1 \mathrm{~mm}$ (SD 1.5), 7.0 $\mathrm{mm}$ (SD 1.5) and $7.1 \mathrm{~mm}$ (SD 1.5), respectively. Those values during stimulation tended to be decreased when compared with those before, although the difference was not statistically significant $(\mathrm{p}=0.09)$. In only 17 of 45 knees of the reconstructed group were the anterior tibial translation values during stimulation significantly decreased $(\mathrm{p}<$ $0.0001)$ compared with those before stimulation. The values in 28 reconstructed knees, of which 22 had detectable SEPs during stimulation, were not decreased.

The mean anterior tibial stiffiness values before, during and after stimulation of the ACL in the normal group were $4.18 \mathrm{~N} / \mathrm{mm}$ (SD 1.70), $4.04 \mathrm{~N} / \mathrm{mm}$ (SD 1.55) and $4.16 \mathrm{~N} /$ $\mathrm{mm}$ (SD 1.68), respectively. The values in normal knees during stimulation were not significantly decreased $(\mathrm{p}=0.15)$ compared with those before stimulation. The mean values before, during and after stimulation of the ACL in the reconstruction group were $3.84 \mathrm{~N} / \mathrm{mm}$ (SD 1.33), $3.80 \mathrm{~N} /$ $\mathrm{mm}$ (SD 1.30) and $3.83 \mathrm{~N} / \mathrm{mm}$ (SD 1.32), respectively. Likewise, the anterior tibial stiffness values in the reconstructed knees during stimulation were not significantly decreased ( $\mathrm{p}=0.12$ ) compared with those before stimulation.

In reconstructed knees, a comparative study was carried out between the 17 subjects whose anterior tibial translation had been significantly decreased by electrical stimulation and the 28 in whom it had not been affected (Table IV). Unpaired $t$-tests showed no significant differences in age, activity score, stability of the knee or muscle strength. However, the joint position sense of the knees, the anterior

Table IV. Data (mean (SD)) of the 17 subjects in the $\mathrm{ACL}^{*}$-reconstructed group whose anterior tibial translation (ATT) had been significantly decreased by electrical stimulation and for the 28 in whom it had not

\begin{tabular}{|c|c|c|c|}
\hline \multirow[b]{2}{*}{ Factors } & \multicolumn{2}{|c|}{ ATT in response to electrical stimulation } & \multirow[b]{2}{*}{ p value } \\
\hline & Decrease & No decrease & \\
\hline Age (yrs) & $29.1(7.4)$ & $29.2(6.5)$ & 0.98 \\
\hline Activity score ${ }^{42}$ & $5.4(1.0)$ & $5.2(0.7)$ & 0.40 \\
\hline Anterior displacement (side-to-side difference, mm) & $1.3(1.4)$ & $1.2(1.9)$ & 0.85 \\
\hline Hamstring muscle strength (ratio of peak torque, \%) & $93.6(13.9)$ & $89.3(14.4)$ & 0.34 \\
\hline Quadriceps muscle strength (ratio of peak torque, \%) & $90.6(13.7)$ & $87.6(13.5)$ & 0.47 \\
\hline Joint position sense inaccuracy of the operated knee $\left({ }^{\circ}\right)$ & $3.34(0.86)$ & $4.21(1.37)$ & $0.02^{\dagger}$ \\
\hline
\end{tabular}


tibial translation of which had been significantly decreased by electrical stimulation, was significantly better $(p=0.02)$ than that of the remainder.

\section{Discussion}

Our results indicate a significant decrease in the anterior tibial translation of the knee by electrical stimulation of the normal ACL, indicating that stimulation of the afferent nerve fibres in the human ACL induces efferent changes in the hamstring and quadriceps muscles. Mechanoreceptors in the human ACL have now been well demonstrated ${ }^{1-3}$ and a possible role for them in generating stabilising and/or protective reflexes has been suggested. ${ }^{35}$ According to DyhrePoulsen and Krogsgaard, ${ }^{16}$ at rest, impulses elicited in the human ACL produce activation of the hamstring muscles, supporting the contention of an automatic ACL-hamstring synergy. The existence of a proprioceptive mechanism arising from mechanoreceptors in the cruciate ligaments and stimulating the thigh muscles has been observed in humans by Tsuda et al. ${ }^{17}$

However, the presence of a reflex activation in response to electrical stimulation to the ACL does not necessarily generate an adequate stabilising force. The question remains as to whether ACL-hamstring reflexes can provide functional protection to the ligament. Our observation that the electrically-stimulated ACL resists anterior tibial translation demonstrates the potential of the ACL-hamstring reflex to provide stability to the knee. According to Wojtys and Huston, ${ }^{36}$ in normal control subjects, the mean anterior tibial translation with the muscles relaxed is $5.4 \mathrm{~mm}$ when a $13.59 \mathrm{~kg}$ step force directed anteriorly is applied to the proximal leg. However, the anterior tibial translation decreases to $2.1 \mathrm{~mm}$ when there is maximal isometric contraction of the muscles of the leg. The ACL reflex may be an essential part of normal function of the knee, although we did not observe such a dramatic decrease in anterior tibial translation.

It is not known how reflexes from mechanoreceptors in the ACL affect the motor neurone pool to muscles in the lower limbs. The reflex may be part of a complicated polysynaptic reflex acting through r-neurones or conducted through slow-conducting afferents from group-III mechanoreceptors. ${ }^{37}$ The pathway of the reflex observed in this study is probably very complex and we do not know the type of afferent which was conducting the impulses in our study.

In at least some patients, such as the normal control group, we have shown a significant decrease in anterior tibial translation of the knee during electrical stimulation of the reconstructed ACL. Evidence provided by our study supports the existence of both afferent and efferent routes, from the central nervous system to the hamstring muscles through neural elements regenerated in the replacement graft.

Tsuda et $\mathrm{al}^{26}$ found a significantly high mean electromyography of between 120 and $140 \mathrm{~ms}$ in biceps femoris in two of three patients during stimulation of the ACL reconstructed with a bone-patellar tendon-bone graft, indicating re-establishment of the ACL-hamstring reflex arc in the reconstructed knee. However, Biedert and Zwick ${ }^{38}$ could not demonstrate a ligament-muscle reflex arc from the graft to the hamstring muscle group. In our study, the anterior tibial translation in 28 reconstructed knees, of which 22 had detectable SEPs during stimulation, was not changed by electrical stimulation. A functional connection between receptors in the graft tissue and the cerebral cortex did not produce a fully restored ACL-hamstring reflex in these knees. Studies of proprioception after reconstruction have suggested that in some patients there is improvement in the injured knee but that in others, a significant deficit remains. ${ }^{29,39}$ A mean period of 26.7 months (24 to 32 ) may not be long enough for reinnervation and re-establishment of the neural pathway to take place consistently. According to Denti et al, ${ }^{40}$ patients with a reconstructed ACL have a clear deficit of motor control compared with normal control subjects, even after several years. Although the transplanted graft shows an ability to adapt to electrical stimulation, it may not achieve the structural identity of the normal ACL.

The joint position sense of the knee, the anterior tibial translation of which had been decreased by electrical stimulation, was found to be significantly better than that of the remainder. These results suggest that an improvement in the joint position sense reflects restoration of the ACL-hamstring reflex after reconstruction, since the test involves afferent activity and motor output which is efferent. However, some authors believe that threshold tests are more sensitive in detecting subtle alterations in proprioception of the knee. $^{41}$

In our study, the existence of the ACL-hamstring reflex arc was shown experimentally, indirectly using electrical stimulation and not mechanical loading. Findings obtained by electrical stimulation may not apply to normal physiological function. We cannot differentiate whether the observed change in stiffness was from biceps femoris or other hamstring muscles. It is clear that mechanoreceptors are present, but that their role is subtle and difficult to measure. However, electrical stimulation is a safe, accurate tool, and constitutes a further step in studying and determining the sensory function of the ACL.

Despite the technical improvements in the management of a torn ACL in the last 20 years, the challenge remains to return the reconstructed knee to a normal pattern of function. Muscle timing, co-ordination and integration need to be addressed. As more sensitive measures are developed and a longer follow-up period for the present patient group is achieved, it will be possible to study the functional significance of the ACL-hamstring reflex and to determine what is needed to facilitate its recovery after reconstruction of the ligament.

No benefits in any form have been received or will be received from a commercial party related directly or indirectly to the subject of this article. 


\section{References}

1. Denti M, Monteleone M, Berardi A, Panni AS. Anterior cruciate ligament mechanoreceptors. Clin Orthop 1994;308:29-32.

2. Schultz RA, Miller DC, Kerr CS, Micheli L. Mechanoreceptors in human cruciate ligaments: a histological study. J Bone Joint Surg [Am]1984;66-A:1072-6.

3. Schutte MJ, Dabezies EJ, Zimmy ML, Happel LT. Neural anatomy of the human anterior cruciate ligament. J Bone Joint Surg [Am] 1987;69-A:243-7.

4. Barrett DS. Proprioception and function after anterior cruciate reconstruction. J Bone Joint Surg [Br] 1991;73-B:833-7.

5. Corrigan JP, Cashman WF, Brady MP. Proprioception in the cruciate deficient knee. J Bone Joint Surg [Br] 1992;74-B:247-50.

6. Jerosch J, Prymka M. Knee joint proprioception in normal volunteers and patients with anterior cruciate ligament tears, taking special account of the effect of a knee bandage. Arch Orthop Trauma Surg 1996;115:162-6.

7. Valeriani M, Restuccia $\mathbf{D}$, Lazzaro $\mathbf{D i}$, et al. Central nervous system modifications in patients with lesion of the anterior cruciate ligament of the knee. Brain 1996;119: 1751-62.

8. Barrack RL, Skinner HB, Buckley SL. Proprioception in the anterior cruciate deficient knee. Am J Sports Med 1989;17:1-6.

9. Beynnon BD, Ryder SH, Konradsen L, et al. The effect of anterior cruciate ligament trauma and bracing on knee proprioception. Am J Sports Med 1999;27:150-5.

10. Borsa PA, Lephart SM, Irrgang JJ, Safran MR, Fu FH. The effects of joint position and direction of joint motion on proprioceptive sensibility in anterior cruciate ligament-deficient athletes. Am J Sports Med 1997;25:336-40.

11. Pitman MI, Nainzadeh N, Menche D, Gasalberti R, Song EK. The intraoperative evaluation of the neurosensory function of the anterior cruciate ligament in humans using somatosensory evoked potentials. Arthroscopy 1992;8:442-7.

12. Johansson H, Sjolander P, Sojka P. A sensory role for the cruciate ligaments Clin Orthop 1991;268:161-78.

13. Solomonow M, Baratta R, Zhou BH, et al. The synergistic action of the anterior cruciate ligament and thigh muscles in maintaining joint stability. Am J Sports Med 1987;15:207-13.

14. Miyatsu M, Atsuta $\mathbf{Y}$, Watakabe $\mathbf{M}$. The physiology of mechanoreceptors in the anterior cruciate ligament: an experimental study in decerebrate-spinalised animals. J Bone Joint Surg [Br] 1993;75-B:653-7.

15. Raunest J, Sager M, Burgener E. Proprioceptive mechanisms in the cruciate ligaments: an electromyographic study on reflect activity in the thigh muscles. J Trauma 1996;41:488-93

16. Dyhre-Poulsen P, Krogsgaard MR. Muscular reflexes elicited by electrical stimulation of the anterior cruciate ligament in humans. J Appl Physiol 2000;89:2191-5.

17. Tsuda E, Okamura Y, Otsuka H, Komatsu T, Tokuya S. Direct evidence of the anterior cruciate ligament-hamstring reflex arc in humans. Am J Sports Med 2001;29: 83-7.

18. Maeda A, Shino K, Horibe S, Nakata K, Buccafusca G. Anterior cruciate ligament reconstruction with multistranded autogenous semitendinosus tendon. $A m ~ J$ Sports Med 1996;24:504-9.

19. Shelbourne KD, Gray T. Anterior cruciate ligament reconstruction with autogenous patellar tendon graft followed by acclerated rehabilitation: a two- to nine year followup. Am J Sports Med 1997;25:786-95.

20. Barrack RL, Lund PJ, Munn BG, Wink C, Happel L. Evidence of reinnervation of free patellar tendon autograft used for anterior cruciate ligament reconstruction. $\mathrm{Am}$ J Sports Med 1997;25:196-202.

21. Goertzen M, Gruber J, Dellmann A, Clahsen H, Schulitz KP. Neurohistological findings after experimental anterior cruciate ligament allograft transplantation. Arch Orthop Trauma Surg 1992:111:126-9.
22. Shimizu T, Takahashi T, Wada Y, et al. Regeneration process of mechanoreceptors in the reconstructed anterior cruciate ligament. Arch Orthop Trauma Surg 1999;119: 405-9.

23. Ochi M, Iwasa J, Uchio Y, Adachi N, Sumen Y. The regeneration of sensory neurones in the reconstruction of the anterior cruciate ligament. J Bone Joint Surg $[\mathrm{Br}]$ 1999;81-B:902-6.

24. Ochi M, Iwasa J, Uchio Y, Adachi N, Kawasaki K. Induction of somatosensory evoked potentials by electrical stimulation in reconstructed anterior cruciate ligaments. J Bone Joint Surg [Br] 2002;84-B:761-6.

25. Kennedy JC, Alexander IJ, Hayes KC. Nerve supply of the human knee and its functional importance. Am J Sports Med 1982;10:329-35.

26. Tsuda E, Ishibashi Y, Okamura Y, Toh S. Restoration of anterior cruciate ligamenthamstring reflex arc after anterior cruciate ligament reconstruction. Knee Surg Sports Traumatol Arthrosc 2003;11:63-7.

27. Myrer JW, Schulthies SS, Fellingham GW. Relative and absolute reliability of the KT-2000 arthrometer for uninjured knees: testing at 67, 89, 134, and $178 \mathrm{~N}$ and manual maximum forces. Am J Sports Med 1996;24:104-8.

28. Skinner HB, Barrack RL, Cook SD, Haddad RJ Jr. Joint position sense in total knee arthroplasty. J Orthop Res 1984;1:276-83.

29. Iwasa J, Ochi M, Adachi $\mathbf{N}$, et al. Proprioceptive improvement in knees with anterior cruciate ligament reconstruction. Clin Orthop 2000;381:168-76.

30. Uchio $\mathbf{Y}$, Ochi M, Fujihara A, et al. Cryotherapy influences joint laxity and position sense of the healthy knee joint. Arch Phys Med Rehabil 2003;84:131-5.

31. Somjen G, Carpenter D, Henneman E. Selective depression of alpha motoneurons of small size by ether. J Pharmacol Exp Ther 1965;148:380-5.

32. Stener B. Experimental evaluation of the hypothesis of ligament-muscular protective reflexes. I: a method for adequate stimulation of tension receptors in the medial collateral ligament of the knee joint of the cat, and studies of the innervation of the ligament. Acta Physiol Scand 1959;48:5-26.

33. Jensen DB, Fischer-Rasmussen T, Magnusson SP, Dyhre-Pouelsen P, Krogsgaard MR. Sonographic guided insertion of electrodes into the cruciate ligaments of the knee. Eur J Ultrasound 1999;10:47-51.

34. Hefti F, Muller W, Jakob RP, Staubli HU. Evaluation of knee ligament injuries with the IKDC form. Knee Surg Sports Traumatol Arthrosc 1993;1:226-34.

35. Beard DJ, Kyberd PJ, O'Connor JJ, Fergusson CM, Dodd CA. Reflex hamstring contraction latency in anterior-cruciate ligament deficiency. J Orthop Res 1994;12 219-28.

36. Wojtys EM, Huston LJ. Neuromuscular performance in normal and anterior cruciate ligament-deficient lower extremities. Am J Sports Med 1994;22:89-104.

37. Fischer-Rasmussen T, Krogsgaard M, Jensen DB, Dyhre-Poulsen P. Inhibition of dynamic thigh muscle contraction by electrical stimulation of the posterior cruciate ligament in humans. Muscle Nerve 2001;24:1482-8.

38. Biedert RM, Zwick EB. Ligament-muscle reflex arc after anterior cruciate ligament reconstruction: electromyographic evaluation. Arch Orthop Trauma Surg 1998;118:81-4.

39. Fremerey RW, Lobenhoffer P, Zeichen J, et al. Proprioception after rehabilitation and reconstruction in knees with deficiency of the anterior cruciate ligament: a prospective, longitudinal study. J Bone Joint Surg [Br] 2000;82-B:801-6.

40. Denti $\mathbf{M}$, Tandelli $\mathbf{P}$, Lo Veter $\mathbf{D}$, et al. Motor control performance in the lower extremity: normal vs. anterior cruciate ligament reconstructed knees 5-8 years from the index surgery. Knee Surg Sports Traumatol Arthrosc 2000;8:296-300.

41. Beynnon BD, Renström PA, Konradsen L, et al. Validation of techniques to measure knee proprioception. In: Lephart SM, Fu FH, eds. Proprioception and neuromuscular control in joint stability. USA: Human Kinetics, 2000:127-38.

42. Tegner $Y$, Lysholm J. Rating systems in the evaluation of knee ligament injuries. Clin Orthop 1985; 198:43-9. 